Research Article

\title{
The Implementation of Complimentary Food on Stunted Children
}

\author{
Rr Dewi Ngaisyah, Selma Avianty \\ Nutrition Study Program, Faculty of Health Science, Universitas Respati Yogyakarta \\ *dewi.fikes@yahoo.co.id
}

\begin{abstract}
Background: The age of 6-24 months old is a transitional period from breast milk to solid food. It is a critical period where children could easily get malnutrition and infection. The stunting prevalence in Kanigoro Village has surpassed the healthy limit (>20\%) and as such, WHO categorized it as a public health nutrition problem. This study figured out the determinant factors of the implementation of complimentary food for breast milk on 6-24 months old stunted children. Methods: This study collected the 5 (five) respondents via purposive sampling methods. The criteria used were the respondents: (1) being 6-24 months old, (2) having the height-for-age z-score value $<-2 \mathrm{SD}$, (3) living in the operational area of the Public Health Center of Saptosari Gunungkidul, and (4) committing to a consensual agreement to be the subjects of the study by submitting a legal informed consent letters. The data of the study were gathered via in-depth interview. The results were then compared to International Food Policy Research Institute (IFPRI) responsive feeding indicators. Results: All of the respondents failed to do the responsive feeding properly and thoroughly. They failed to spoon feed the children, or to help the children eat by themselves, to be patient and to persuade their children to eat, to provide food in safe environment, to make feeding time as also learning time, and to care for the children. The response feeding predisposition factors are the limited time and the respondents' perception to their children. The enabling factors are the availability and accessibility of resources. The empowering factors are the motivation from family members. Conclusion: It is recommended to involve the results of this study in basic policies formulations of many public health centers. It is expected to help children get better food intake and to optimize their growth.
\end{abstract}

Keywords: Fish, Consumption, Economic, Stunting.

\section{INTRODUCTION}

Stunting is a failed process to hit potential linear growth. It is calculated via length/height - for - age measurements. WHO stated that there were 186 million stunted children in the world with $90 \%$ of them living in 36 developing countries, including Indonesia. Based on the Basic Health Research (Riskesdas) data in 2010, it was gathered that the number of stunted children in Indonesia had hit $35.6 \%$. Children aged 24-36 months old occupied $41.4 \%$ of the data. This stunting prevalence was higher than the malnutrition $(17.9 \%)$, wasting $(13.3 \%)$ and obesity (14\%) prevalence (1).

The short term problems that stunting causes are: the raising number of mortality and morbidity, the cognitive 
developmental disorders, psychomotoric and mental disorders in children that are associated to poor psychosocial functions in adolescence (2). In addition, the stunted children will be more likely to get degenerative diseases and have lower chance to get proper job in adulthood (3).

The causes of stunting are inappropriate nutritional intake, infection and caretaking method. Failure to fulfill the nutritional needs is usually associated to the lack of food quantity or the possibility of infection. Nevertheless, many studies showed that it can also caused by a large variety of factors, including parenting, and more particularly the children's dietary habit (4). A study in Latin America has proved the correlation of the implementation of complementary food for breast milk and exclusive breast milk to the children's height-for-age measurements (5). The proper implementation of dietary habit in children does not only cater around the kinds of food given, but also the way the food is processed, the when and where the food is prepared, and the people responsible (6).

The ability of caretakers to actively provide children responsive feeding are measured by considering several factors: 1) the way they feed based on the age of the children, 2) the way they persuade the children to eat, 3) the way they respond to the lack of appetite, 4) where they feed the children, and 5) the interaction between them and the children (6). Another study has also proven how the implementation of proper dietary habit has persuaded the children to eat solid food and improved the children's confidence to eat without help (7). In addition, proper care during feeding time may involve psychosocial concepts that help grow the children's mental and cognitive ability. Children begins to explore solid food in age 6 to 24 months old (8). It is a transitional period from breast milk to solid food. Therefore it is a critical period where children could easily get malnutrition and infection. It is also a golden period to teach some concepts of food that will affect the children's dietary habit later on.

The implementation of complementary food for breast milk is included in the caretakers' healthy habit in regards of the children's dietary habit. There are several factors affecting this implementation, from the caretakers to the surrounding environment. Krauter and Green classified those factors into three major factors: predisposition factors, enabling factors (the available resources) and empowering factors (references). Predisposition factors in feeding time are internal factors from the caretakers themselves, such as their knowledge, perception, and the time availability. Enabling factors are the availability of food that is related to the economic factors. Empowering factors are motivation from the family members, such as the children's fathers and grandparents.

Based on the nutritional status screening done by Gunungkidul Board of Health, it is gathered that the number of stunted children reached $22.66 \%$ with the highest being in Saptosari. One of the areas in Saptosari with the case of stunted children is in the operational area of Saptosari Public Health Service. Therefore, it has become curiosity to figure out the implications of complementary food for breast milk implementation in stunted children and 
the affecting causes in operational areas of Saptosari Public Health Service.

\section{METHODS}

The study was conducted in the operational areas of Saptosari Public Health Service, Gunungkidul, Yogyakarta, in March-June, 2018. It was a descriptive qualitative study, using observation and in-depth methods.

Total respondent of this study were 5 children. The respondents were selected via purposive sampling method, by considering inclusion and exclusion criteria. The inclusion criteria set were caretakers (with 6-24 months old children having $\mathrm{z}$-score value under -2 SD) in operational areas of Saptosari Public Health Service. They were also asked to sign informed consent letters that stated their consent to be the subjects of this study.

The dependent variable of this study was the dietary habit of the stunted children. To figure out the dietary habit of complementary food for breast milk, an observation was made. There were also 20-item questionnaire delivered that were further confirmed through recalling interviews. The results were then compared to IFPRI responsive feeding indicators. The observation was done in three different feeding time in different days at the least. The independent variable of the study were the predisposition factors (knowledge, perception and the caretakers' time availability), enabling factors (available budget for the food), empowering factors (the children's fathers, grandparents or other family members). The data were gathered via in-depth interview. The indept interview was done three times at the least for each respondent. The data included 1) the subjects' identity such as the names, ages and the children's nutritional status; 2) the names, ages, address, jobs, and the last educational degree of the mothers'; 3 ) the number of the children's family members, the monthly spending rate, the observational data and the in-depth interview data with the respondents.

The data were analyzed using the qualitative data analysis. They were presented based on the collected data before they were concluded. These qualitative data were then processed based on the variables using induction method.

\section{RESULT}

This study was conducted in the operational areas of Saptosari Public Health Service, in Kanigoro. Kanigoro has 10 Integrated Service Centers with all of them having chronic nutritional problems (stunting). Based on the length/height-for-age of the five children, it was positive that they were stunted as the z-score numbers were measured only -2.75 SD to -3.8 SD. The social and economical status of the five respondents' family were categorized as average to poor with their monthly spending averaging on $\mathrm{Rp} 1.454 .154,15$. The number is below Gunungkidul's minimum wages policy. From the five respondents, the heads of the family took quite a variety of jobs. They were workers of private sectors, entrepreneurs, and fishermen.

Three of the five children were aged 24-59 months old. This means that these children had begun to feed themselves. In this period, children's motoric and verbal skills are maturing, which tremendously help the feeding 
process. Careful monitoring is needed to ensure optimal growth and development. There were three male children from the five, which also means more active physical activity even during the feeding time.

Table 1. Characteristics of Children and their Mothers

\begin{tabular}{ll}
\hline Characteristics & n \\
\hline Children's Age (in months) & 2 \\
$6-24$ & 3 \\
$24-59$ & \\
Genders & 2 \\
Male & 3 \\
Female & \\
Mothers' Age (in years) & 5 \\
$25-35$ & \\
Mothers' Educational Degree & 1 \\
Elementary School & 1 \\
Junior High School & 3 \\
High School & \\
Mothers' Job & 3 \\
Housewives & 1 \\
Merchants & 1 \\
Private Workers & \\
Family Status & \\
Nuclear Family & \\
Extended Family & \\
Caretaker Responsible in & \\
Feeding Time & \\
Mothers & \\
Grandmothers & \\
Income & \\
Below Gunungkidul Minimum \\
Wage Policy 2018 \\
Above and equal to \\
Gunungkidul Minimum Wage \\
Policy 2018 & 3 \\
\hline
\end{tabular}

The mothers' characteristics were analyzed based on their age, education level and job. One of the respondents had a working mother, which greatly affects the caretaking method and time availability. This results in the involvement of another individual as the responsible caretaker in feeding the child: the grandmother. Two of the five respondents live with their extended family. It has an impact in the amount of house chores the mothers had to do and other family members' role in feeding the children.

\section{DISCUSSION}

Responsive feeding method is the skills a caretaker needs to have to feed the child actively and responsively. WHO mentioned five recommendations in responsive feeding method that are explained as follows. The first recommendation is to feed directly or assist in eating. The respondents showed good motoric skills regarding this matter. However, the caretakers' respond to their hunger was still under satisfactory level. The second recommendation is to feed slowly and patiently and encourage the children to eat. It is common for caretakers to know positive strategies to encourage the children to eat. However, this had not been the case. The third recommendation is to utilize various strategies if a child refuses food. Not many caretakers know positive strategies if the respondents refuse to eat. Therefore, the respondents had not shown any expected results. The fourth recommendation is to feed the children in a protected environment. The caretakers were not always sitting with the respondents during feeding time, so that the mothers could not always come to help when problems arise. This implies the lack of attention from the caretakers. The last recommendation is that feeding times are moment. In practicality, the caretakers failed to make feeding times a moment to learn feeding, types of food, or the proper way to eat food.

From all of the above five recommendations of responsive feeding, only the first one that was a success. One of the respondents was still aged 12 
months old and was still fed directly by the caretakers. The other four had been assisted. Most caretakers allowed the children to feed themselves (9), even though sometimes they still need to be assisted, i.e when they were ill or when they had no appetite. The frequency highly depends on the caretakers' time availability.

The second recommendation indicates the caretakers' knowledge of positive reinforcement to encourage the children to eat. Most caretakers understood what to do, however they chose not to abide. This was correlated to the caretakers' daily activity and time availability. The most oftenly done was that they showered the children with praisings, asked the children to open their mouth widely and then chew their food, or engaged the children in conversations. There was another way, which was getting the respondents to eat around the children their age. Another strategy was also mentioned, which was taking the respondents for a walk, or feeding them while watching TVs or playing. However this could only be done if the children could not eat by themselves and was highly not recommended since this can disturb their focus on eating.

Caretakers' responds to the respondents who refuse food were varies. Most of them were apathetic, especially when there were abundant house chores. Some caretakers mentioned that they changed the dining menu or assisted the children with verbal encouragement. However, it greatly depended on the caretakers' mood. On responsive feeding, WHO recommends changing the dining menu, food texture or taste if a child refuse the food. Nevertheless, there were few choices the respondents could have at home. The respondents would usually request the food they like if they did not like what were available. Although, the food they chose lacked of nutritional values, such as instant noodles.

Regarding the fourth recommendation of responsive feeding, there were several points to be considered. There was one adult family member who fed the child with separated utensils. There were other caretakers sitting near the child. Two of the three respondents had consistent adults who fed them, however the rest of them did not have any other adults responsible to be their caretakers. All of the respondents had different utensils. The caretakers did not always sit beside the respondents. Sometimes they allow the children to feed themselves while watching TVs, or while they were around children their age. There was also quite a distance between the respondents and the caretakers, because the caretakers had to divide their attention to the piling house chores too. Therefore, the caretakers were not always capable to help the respondents if anything happened. They could not pay close attention to the respondents either. This was also the case when the feeding time happened outside.

As the fifth recommendation stated, the children should use their feeding time as a bonding moment. Some caretakers engaged the respondents in positive interaction during feeding time. They also allowed the children to feed themselves and provided finger food. However, they rarely taught the children how the food is processed, types of food or the proper way to eat food.

Predisposition factor is an internal behavioral-changing factor. Regarding feeding time, the caretakers' time 
availability is a fairly crucial. Undivided time and attention are better than forcefeeding for the children to be encouraged to feed themselves. From the eight caretakers, four of them were working mothers having been working as workers in private sectors or merchants. They had exhausting time-consuming job, not to mention the house chores. Caretakers who worked as a worker of private sectors (R.1) relayed their caretaking duty to another family members who lived in the same house: the grandmothers. This also actively affected the feeding process because of the difference in characteristics.

Surprisingly, time availability had also become an issue to caretakers who worked as housewives. The large number of family members and the never ending house chores oftentimes were timeconsuming and tiring. In the end, they had little time to care for their children's needs.

Aside of time, another factor that affected the feeding process were the caretakers' knowledge and perception of the respondents. All caretakers were not familiar with the concept of responsive feeding thoroughly, only generally. This was the reason caretakers could not implement all of the points recommended above. The caretakers' perception of the children affected the caretakers' responsiveness during feeding time. When a caretaker has had a specific mindset about a child, he or she will know what to do and not to do so the said child would eat.

The most on point enabling factor is the periodically budget availability to buy food. This corresponded with the social and economical status of the family. Two of the three caretakers had low income, which was below Gunungkidul minimum wage policy, which was RP $1.454 .154,15$ by the year of 2018. Three other respondents lived with their respective extended family, while the rest of them did with their 3-5 person nuclear family. This greatly affected the monthly spending budget. The social and economy status clearly affected the variety of the food a child can get. This became important when the children refuse to eat. When there was no other food to provide, the children were left with two options: to eat what was available or to not eat at all.

Budget also affected the caretakers' time availability and perception. Some caretakers had to go to work because the income from their husbands alone was not enough. In some cases, the head of the family did not have stable job. Some fathers had deceased so the mothers had to take over the role. This resulted in even more lack of attention. Therefore, responsive feeding recommendations were no longer applicable.

There were positive and negative factors of empowering factor in this study. The empowering factors became negative when there was lack of help from other family members in doing house chores, resulting in unfocused attention and limited time. The influence of patriarchal culture in Indonesia created a mindset where female family members had to do house chores. Not many male family members were willing to help. The positive empowering factors were the help from other family members, such as grandmothers, aunts or other older members. Underage members, i.e older children, or continuously changing adults should not be considered as a help, since this could cause confusion that was 
reflected in different levels of responsiveness.

Determining food choices based on a child's age is highly important because of its dependency on the general psychomotor and motoric skills development. It is even more important on growing children, particularly children under 2 years old. This directly affected the way they eat and the nutritional intake. An example of a proper way to teach a child eating is to begin from finger food on the age of 9-12 months old. From that point on, children are allowed to feed themselves (with assistance) on the age of one year old and over. This trains their motoric skills simultaneously.

McDonald stated that a refusal to food and other eating problems are a common case in children. The frequency ranges from 16-75\% (10). Mostly, it does not affect their growth but it can. Common causes of food refusal were: 1) too much drink, 2) overindulgence in semi-solid food in the first 2 years of life, 3) caretakers' inability to provide a large variety of food, 4) irregular feeding time, 5) unappetizing food, 6) parental anxiety, 7) caretakers' unwanted responses or emotional impulses and 8) caretakers' manipulative behavior. To overcome this problem, caretakers are recommended to: 1) provide quite a variety of food (the choices, textures and tastes), 2) prepare appetizing menu and 3) creatively encourage the children to eat (11).

Many studies on responsive feeding and malnutrition in developmental countries had proven how verbal interaction between the caretakers and the children improved the children's responsiveness while feeding (7). Aboud had studied malnutrition in Bangladesh and hand found that changing the caretakers' behavior had actively encouraged the children to eat. The even feed themselves (8). On the other had, a study conducted in a more modern countries showed a correlation between high income parents with a less responsive feeding method. This further consistently correlated with obesity in children. These studies had proved how responsive feeding is an immediate importance, especially for stunted children to raise their responsiveness in feeding, improve their motoric skills from self-feeding, and achieve better nutritional status.

This study concluded that predisposition factors was the most influencing factors in responsive feeding (12). These were the caretakers' knowledge, perception, and time availability. This study showed how the caretakers' perception created a caretaking method and directly affected their interaction with the children. These were crucial to optimize feeding time. Budget (the enabling factor) were correlated with time availability because low social and economic status forced the caretakers to leave for a job. Hence, it lessened the time to spend with their children. However, this would not be a problem if the caretakers have another family members to help them implementing responsive feeding method when they were not available.

\section{CONCLUSION}

This study was inconclusive because none of the caretakers of the five respondents' properly implemented the responsive feeding method. None of these responsive feeding methods as direct feeding, feeding with assistance, 
responding to food refusal, slow feeding, being patient and encouraging, feeding in save environments and feeding as a moment were applied as suggested. Predisposition factors in responsive feeding were about the caretakers' time availability and perceptions to the children. The enabling factors were availability and access to resources. The empowering factors were the support from family members.

It was of urgent importance for the public health service to provide information and campaign in responsive feeding to help optimize the children's growth and development. It was expected from the future researchers to conduct a case control study to find the correlation between responsive feeding in stunted and normal children in various age with the caretakers' job.

\section{ACKNOWLEDGMENT}

The autors are thankful to the subjects in the study. We are also grateful for the financial support of the Community Dedication and Research Directorate (PPPM) of Universitas Respati Yogyakarta.

\section{CONFLICT OF INTEREST}

There is no conflict of interest to this study.

\section{REFERENCE}

1. Badan Penelitian dan Pengembangan Kesehatan

Kementerian Kesehatan Republik Indonesia. Riset Kesehatan Dasar Tahun 2010. Laporan Nasional 2010. Jakarta; 2013.

2. Stewart CP, Iannotti L, Dewey KG, Michaelsen KF, Onyango AW. Contextualising complementary feeding in a broader framework for stunting prevention. Matern Child Nutr. 2013;9(S2):27-45.

3. Sawaya AL, Martins P, Hoffman D, Roberts SB. The Link Between Childhood Undernutrition and Risk of Chronic Diseases in Adulthood: A Case Study of Brazil. Nutr Rev. 2003;61(5):168-75.

4. Astari L, Nasoetion A, Dwiriani C. Hubungan Karakteristik Keluarga, Pola Pengasuhan dan Kejadian Stunting Anak Usia 6-12 Bulan. 2005;29:40-6.

5. Teshome B, Kogi-Makau W, Getahun Z, Taye G. Magnitude and determinants of stunting in children underfive years of age in food surplus region of Ethiopia: The case of West Gojam Zone. Ethiop J Heal Dev. 2010;23(2).

6. Ruel MT, Menon P. Child Feeding Practices Are Associated with Child Nutritional Status in Latin America: Innovative Uses of the Demographic and Health Surveys. J Nutr. 2002;132(6):1180-7.

7. Bentley ME, M.Wasser H, CreedKanashiro HM. Responsive feeding and child undernutrition in. $\mathbf{J}$ Nutr. 2011;141:502-7.

8. Aboud FE, Shafique S, Akhter S. A Responsive Feeding Intervention Increases Children' s Self-Feeding and Maternal Responsiveness but Not Weight Gain. J Nutr. 2009;139:1738-43.

9. Walker, Chang S, Powell C, Grantham-Mcgregor S. Effects of early childhood psychosocial stimulation and nutritional supplementation on cognition and education in growth-stunted Jamaican children: Prospective 
cohort study. Lancet.

2005;137:2464-9.

10. MacDonald A, Holden C. Nutrition and Child Health. London: Harcourt Publisher Limited; 2000. 55-56 p.

11. Harbron J, Booley S, Najaar B, Day C. III. Responsive feeding: establishing healthy eating behaviour early on in life. South African J Clin Nutr. 2013;26(S):141-9.

12. Hurley KM, Cross MB, Hughes SO. A Systematic Review of Responsive Feeding and Child Obesity in HighIncome Countries. J Nutr. 2011;141(3):495-501. 